\title{
Morphologic changes due to human chorionic gonadotropin in the rat testis: Role of vascular endothelial growth factor
}

\author{
Alfonso Papparella ${ }^{1}$, Fabiano Nino ${ }^{1}$, Carmine Noviello ${ }^{2}$, Mercedes Romano ${ }^{2}$, Serenella Papparella ${ }^{3}$, \\ Orlando Paciello ${ }^{3}$, Antonio Agostino Sinisi ${ }^{4}$ \\ ${ }^{1}$ Department of Pediatric Surgery, II University of Naples, Naples, Italy \\ ${ }^{2}$ Department of Pediatric Surgery, Salesi Pediatric Hospital, Ancona, Italy \\ ${ }^{3}$ Department of Pathology and Animal Health, Section of Pathologic Anatomy, Faculty of Veterinary Medicine, University of Naples \\ Federico II, Naples, Italy \\ ${ }^{3}$ Department of Endocrinology, II University of Naples, Naples, Italy \\ Email: alfonso.papparella@unina2.it
}

Received 12 April 2013; revised 11 May 2013; accepted 19 May 2013

Copyright (C) 2013 Alfonso Papparella et al. This is an open access article distributed under the Creative Commons Attribution License, which permits unrestricted use, distribution, and reproduction in any medium, provided the original work is properly cited.

\section{ABSTRACT}

Introduction: Human chorionic gonadotropin (hCG) has an important role in the regulation of reproductive system and a high capacity to stimulate angiogenesis by secretion of vascular endothelial growth factor (VEGF). It could be also used for medical treatment of cryptorchidism, as it stimulates Leydig cells to produce testosterone, but its use has been discussed. Aim of the study was to evaluate the testicular morphological changes due to cyclic administration of hCG possibly related to VEGF effect. Methods: 80 pre-puberal male Sprague-Dawley rats were randomly divided in two groups hCG $(50 \mathrm{U} / \mathrm{I} /$ $\mathrm{Kg})(\mathrm{n}=55 / \mathrm{S})$ and placebo $(\mathrm{n}=25 / \mathrm{C})$ treated. The animals were sacrificed respectively after one (S1 $n=$ 10; $C 1 n=5)$, two (S2 $n=10 ; C 2 n=5)$ and three weeks of hCG or placebo treatment ( $S 3 \mathrm{n}=35$; C3 n = 15); a blood serum was obtained for evaluation of plasmatic testosterone. The testis, prostates, epididymides and seminal vesicles were drawn and weighted. Specimens were fixed in formalin and coloured by hematoxylin-eosin. Morphometric analysis of Leydig cell number, nuclear area and perimeter was carried out. Immunoistochemistry for VEGF has been performed with the avidin-biotin peroxidase technique. Statistical differences between groups, each of different age, were calculating using Student's T-test. Results: After the first week of hCG treatment it has been observed an increased testicular weight and volume $(+/-6 \%)$ in experimental respect to control group. This result was not observed after the second and third week of treatment. Significant variations were also observed in the mean prostate weight, whereas mean seminal vesicles weight was significant in the $S 2$ and $S 3$ groups respect to control. In the hCG treated rats it has been observed a poor differentiation of the seminiferous epithelium, with high Leydig cell evidence and increased intertubular eosinophilic material. An interstitial edema was demonstrated without inflammatory cell changes. Morphometric analysis confirmed an increased number of Leydig cells that were always strongly immunostained for VEGF. Low-medium reactivity was present in spermatogonial, peritubular, endothelial and Sertoli cells. Testosterone plasmatic values showed a statistically significant and progressive increase. Conclusions: hCG treatment clutters the germinative line and modifies VEGF testicular expression, suggesting its role in male reproductive system. The increased number of Leydig cells and the immunostaining for VEGF suggests an intense interstitial and metabolic arrangement. The morphologic modifications induced by hCG treatment and its influence on testis function raise the question about its use in the medical treatment of cryptorchidism.

Keywords: Cryptorchidism; hCG; VEGF; Hormonal Treatment

\section{INTRODUCTION}

It is well known that testicular functions such as steroid genesis and spermatogenesis are primarily regulated by 
pituitary gonadotropins.

Both Luteinizing Hormone (LH) and human chorionic gonadotropin (hCG) promote hormonal synthesis on Leydig cells. In the male, hCG/LH receptors are expressed in the gonads and are also found in extragonadal organs, including the prostate, epididymis and seminal vesicles $[1,2]$.

In the testis, a close association between Leydig cells and capillaries has been demonstrated. The endothelial cells of the testis show a higher proliferation rate when compared to most other organs. This rate could be increased by hCG stimulation of Leydig cells. In addition, hCG influenced testicular blood flow, and increased vascular permeability in rat testis [3].

This phenomenon could be mediated by vascular endothelial growth factor (VEGF), a major regulator of blood vessel growth and permeability [4].

VEGF is also known as Vascular Permeability Factor (VPF) with an effect 50,000 times higher than histamine [3]. It is well known that Leydig cells secrete VEGF and its receptors, VEGFR 1 and 2 are expressed on blood vessel $[2,5]$. Despite their structural similarity the two VEGF receptors are functionally different: VEGFR-2 is required for the development of the endothelial lineage whereas VEGFR-1 plays a role in the organization of the vascular endothelium [6].

Hormonal treatment with Human Chorionic Gonadotropin (hCG) or gonadotropin releasing hormone may be initially administered for cryptorchidism because it should promote the testicular descent in about $10 \%$ $65 \%$ of cases [7]. The theoretical basis for its use is to stimulate the Leydig cells to produce testosterone, inducing inguinal-scrotal testicular descent. It has been reported in experimental and human studies the possible controversial effect of hCG therapy. In adult rats a single dose of hCG can acutely induce disruption and spermatogenesis disorder, seminiferous tubule damage and inflammation-like changes in testicular microcirculation [8]. Furthermore cryptorchids patients who underwent surgery had an increased volume and number of spermatogonia per tubule respect to the patient who underwent unsuccessful hormonal treatment, suggesting that it may harm germ cells [9].

The aim of the present study was to evaluate the effect of hCG cyclic administration, in rats, on reproductive system and to verify the role of VEGF in these changes.

\section{MATERIAL AND METHODS}

80 prepuberal male Sprague-Dawley rats $(1-2$ months old, weight $100-120 \mathrm{~g}$ ) were the subjects of the study. The experimental protocol was conducted after approval by the institutional animal care of Second University of Naples, Faculty of Medicine, in accordance with the Na- tional Institute of Health guidelines for use of experimental animals. The rats were housed in suitable environmental conditions $\left(12 \mathrm{~h}\right.$ daylight at $22^{\circ} \mathrm{C}$ temperature), with food and water ad libitum under veterinary medical control.

\subsection{Experimental Study}

On the day of the study, the rats were randomly assigned to one of two groups as follows: Placebo pre-treated, designated as "C" group, and HCG pre-treated group designated as " $\mathrm{S}$ " group. Every group has been divided in three subgroups and three set of determination were obtained when the animals were sacrificed, by an overdose of Penthobarbital $(100-200 \mathrm{mg} / \mathrm{Kg})$, respectively after one ( $\mathrm{S} 1 \mathrm{n}=10 ; \mathrm{C} 1 \mathrm{n}=5)$, two $(\mathrm{S} 2 \mathrm{n}=10 ; \mathrm{C} 2 \mathrm{n}=5)$ and three weeks of treatment $(\mathrm{S} 3 \mathrm{n}=35 ; \mathrm{C} 3 \mathrm{n}=15)$. The rats were pre-treated by intramuscular injection with placebo (PBS) or hCG $(50 \mathrm{IU} / \mathrm{Kg})$ every second day of the study period. The hCG doses and timing of pretreatment were based on previous studies [10].

Each determination consisted in a blood sample for testosterone levels, dosed with RIA technique. The testis, prostates, epididymides and seminal vesicles was drawn and weighted, and specimens of the testis were taken for immunohistochemical analysis.

\subsection{Histological Technique}

Testicle samples were fixed in $10 \%$ formalin and embedded in paraffin. Section of 4-micron thickness were then coloured by hematoxylin-eosin. Immunohistochemistry has been performed using the avidin-biotin peroxidase technique with monoclonal antibody against Vascular Endothelial Growth Factor Ab-3 JH121 clone, 1/100 diluition; sections were submitted to proteolysis by three cyclic 5 minutes treatment and incubated for two hours with VEGF AbI at room temperature. Control sections have been prepared using normal serum, without antibody. Morphometric analysis of the interstitial cell population was carried out by evaluation of Leydig cell number, nuclear area and perimeter. This was accomplished by selecting for each testicular sample with low magnification (objective 10×) 10 areas. Subsequently it has been evaluated for each area by a manual calculation the nuclear Leydig numbers with high magnification $(40 \times)$. Every nucleus has been morphometrically evaluated by picture analyzer, carefully considering the area and perimeter.

\subsection{Computations and Statistical Analysis}

Statistical differences between groups were calculating using Student's t-test at different weeks of treatment. All data were expressed as mean $+/-$ SM; $p<0.05$ was con- 
sidered statistically significant unless otherwise specified.

\section{RESULTS}

The mean reproductive system organs weights are illustrated in the Table 1. After the first week of treatment we observed a significant increase of mean testicular weight in $\mathrm{S} 1$ group respect to $\mathrm{C} 1$. This result was not observed after the second and third week of treatment. In the control group C2 and C3 we observed an increase of testicular weight about $14 \%$ respect to the experimental group (S2; S3), but these variations were not statistically significant.

Mean prostate weight variations were statistically significant in all experimental groups during the study periods. Mean seminal vesicles were significant in the S2 and S3 groups respect to control (Table 1).

Plasmatic testosterone values showed a progressive and significant increase in all experimental, compared with control groups (Table 2).

\subsection{Histological Examination}

The testis of the rats pre-treated with hCG showed no macroscopically modifications except for an apparent increased consistency of albuginea.

In the hCG treated rats it has been observed a poor differentiation of the seminiferous epithelium, and increased intertubular eosinophilic material (Figure 1). These histopathological changes were not observed in the $\mathrm{C}$ group (Figure 2). Furthermore an interstitial edema was demonstrated without inflammatory cell changes, more evident during the first week of treatment. Leydig cells were always strongly immunostained for VEGF (Figure 3) whereas low immunostaining was contained in peritubular and endothelial cells. They displayed eosinophilic abundant cytoplasm with distinct cell margins, rounded nuclei with prominent nucleoli and peripheral ring of heterochromatin. Low-medium reactivity was present in spermatogonial and Sertoli cells (Figure 4).

\subsection{Morphometric Investigation}

The data shown in Table 3 confirm the significant and progressive increase of the Leydig cells in the treated rats. Data related to Leydig cells determination of nuclear area and perimeter showed a progressive increase of their values in the three weeks of treatment, but these data are not statistically significant (Table 3).

\section{DISCUSSION}

This experimental study was designed to verify the effect of hCG stimulation on rat testis and to assess the possible VEGF implication in the testicular tissue changes.

Hormonal therapy may be used in the medical treatment of undescended testis. The theoretical basis for its use is to stimulate the Leydig cells to produce testoster-

Table 1. Mean reproductive system organs weight (grams) for study groups by study periods.

\begin{tabular}{|c|c|c|c|c|c|c|}
\hline & $\mathrm{S} 1$ & $\mathrm{C} 1$ & $\mathrm{~S} 2$ & $\mathrm{C} 2$ & S3 & $\mathrm{C} 3$ \\
\hline Testis & ${ }^{*} 1.02$ & 0.96 & 1.43 & 1.6 & 1.74 & 2.1 \\
\hline Prostate & ${ }^{*} 0.07$ & 0.04 & ${ }^{\circ} 0.13$ & 0.09 & $\S_{0.19}$ & 0.14 \\
\hline Seminal vesicles & 0.05 & 0.04 & ${ }^{\circ} 0.14$ & 0.08 & ${ }^{\S} 0.37$ & 0.22 \\
\hline Epididimous & 0.14 & 0.14 & ${ }^{\circ} 0.26$ & 0.23 & 0.38 & 0.39 \\
\hline
\end{tabular}

Values are mean +/- SEM; ${ }^{*} \mathrm{p}<0.05$ vs C1; $\stackrel{\circ}{\mathrm{p}}<0.05$ vs C2$;{ }^{\S} \mathrm{p}<0.05$ vs C3.

Table 2. Serum testosterone values $(\mathrm{pg} / \mathrm{ml})$ for study groups by study periods.

\begin{tabular}{ccccccc}
\hline & $\mathrm{S} 1$ & $\mathrm{C} 1$ & $\mathrm{~S} 2$ & $\mathrm{C} 2$ & $\mathrm{~S} 3$ & $\mathrm{C} 3$ \\
\hline $\begin{array}{c}\text { Mean serum testosterone } \\
\text { (values ng/ml) }\end{array}$ & $\begin{array}{c}1.15^{*} \\
\text { (Range 0.02 - 2.9) }\end{array}$ & $\begin{array}{l}\text { (Range } 0.009-0.065) \\
\text { (Range 1.92 - 9.86) }\end{array}$ & (Range 0.43 - 1.95) & (Range 3.5 - 16.4) & $($ Range 0.8 - 3.6) \\
\hline
\end{tabular}

Values are mean $+/-\mathrm{SEM} ;{ }^{*} \mathrm{p}<0.05$ vs $\mathrm{C} 1 ; \mathrm{p}<0.05$ vs $\mathrm{C} 2 ;{ }^{\circledR} \mathrm{p}<0.05$ vs $\mathrm{C} 3$.

Table 3. Histologic morphometric variables: Leydig cells number nuclear area and perimeter for study groups by study periods.

\begin{tabular}{ccccccc}
\hline & S1 & C1 & S2 & C2 & S3 & C3 \\
\hline Number of Leydig cells & ${ }^{*} 187$ & 117 & 252.2 & 155.5 & $\S_{211}$ & 82.5 \\
Area $\left(\mu \mathrm{m}^{2}\right)$ & 20.92 & 19.83 & 21.13 & 20.15 & 25.3 & 23.22 \\
Perimeter $(\mathrm{mm})$ & 187.96 & 16.76 & 18.08 & 17.96 & 19.72 & 19.09 \\
\hline
\end{tabular}

Values are mean +/- SEM; ${ }^{*} \mathrm{p}<0.05$ vs $\mathrm{C} 1 ; \stackrel{\mathrm{p}}{\mathrm{p}}<0.05$ vs $\mathrm{C} 2 ;{ }^{\S} \mathrm{p}<0.05$ vs C3. 


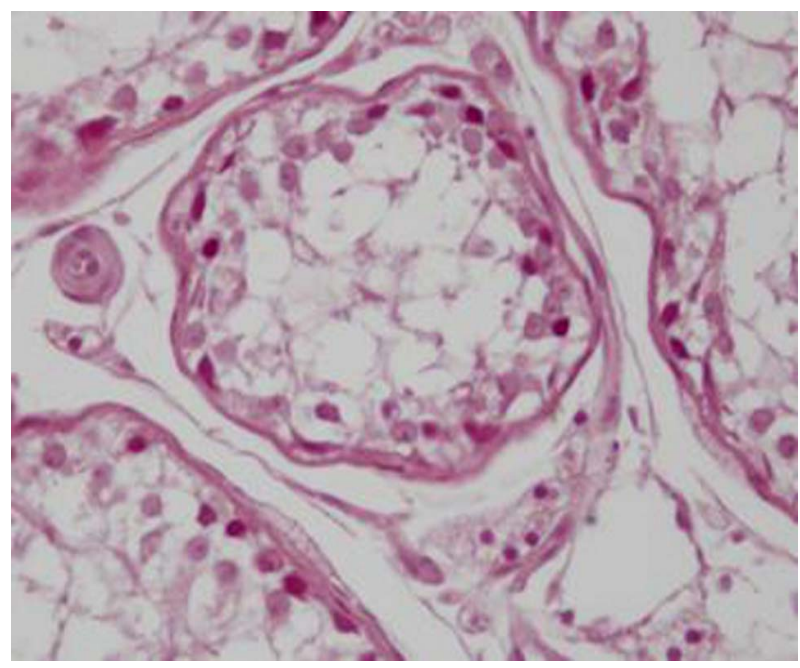

Figure 1. S3 group: Poor differentiation of the seminiferous epithelium, with high Leydig cell evidence and increased intertubular eosinophilic material.

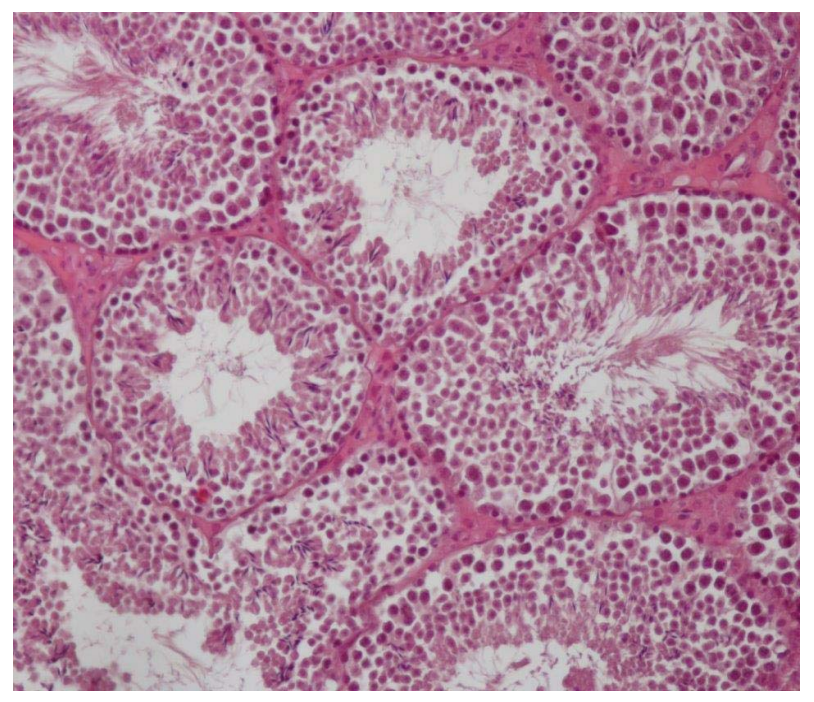

Figure 2. C3 group: Normal aspect of the seminiferous epithelium.

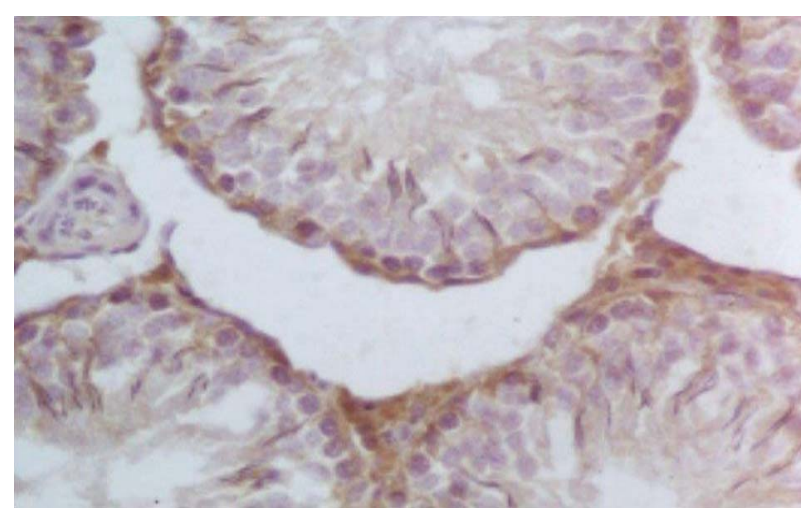

Figure 3. S3 group: Representative VEGF immunohistochemistry in hCG treated testes $(400 \times)$. Increased immunoreactivity in Leydig cells in testes treated with hCG.

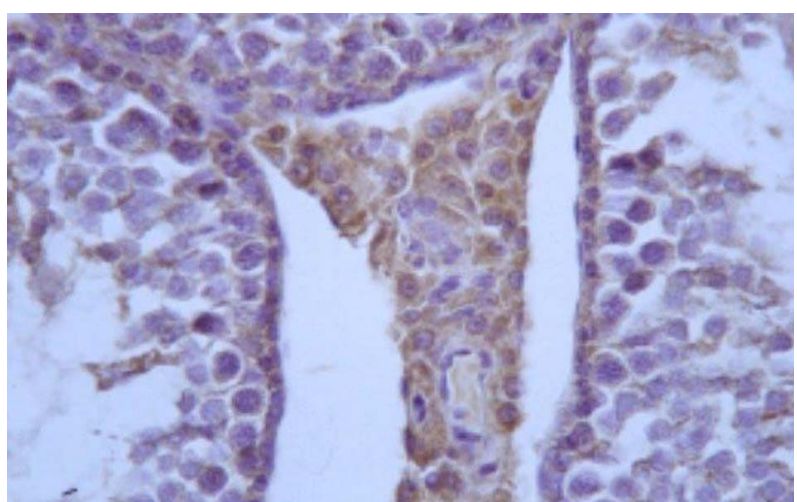

Figure 4. S3 group: VEGF medium reactivity in basal germinative line.

one, and thereby induce testicular descent [7]. The hCG treatment has its action on all male reproductive system (testis, prostate, seminal vesicles and epididymis). The mean testicular weight variations during the study periods testify that the target of hCG treatment is not only the testis but also all the reproductive system. In the first week hCG stimulation principally increases the mean weight of testes probably mediated by testosterone increase. In this period gonadotropin and testosterone are physiologically suppressed, thereby the impact of early hCG treatment is important [9]. In our study, in the hCG treated rats it has been observed a poor differentiation of the seminiferous epithelium, with high Leydig cell evidence and increased intertubular eosinophilic material. An interstitial edema was demonstrated without inflammatory cell changes, and these modifications were more evident during the first week of treatment. Morphometric analysis confirmed a progressive increase of Leydig cell number. These changes suggest that hCG treatment causes an intense metabolic arrangement and may have several effects on the testicular vasculature. We have observed an increased testicular weight in the first week of treatment. This effect was not confirmed during the second and third week of treatment even if a non significant weight decrease was evidentiated in experimental respect to control groups. Leon et al. demonstrated that hCG administration in the rats showed different patterns according to the age. hCG has an action on mesenchimal precursors in young rats, promoting their differentiation. These effects are minimal in differentiated Leydig cells in older animals [11]. It has been reported in adult and immature rats that testosterone secretion following hCG administration shows a biphasic pattern and after seven days of treatment the number of unstimulated receptor was lower than control.

These data indicate that recovery of testicular LH receptors, after hCG administration in immature rats, occurs more rapidly and could justify the difference in the mean weight of the testis. hCG treatment resulted in a 
significantly increase of Leydig cells. This increase number and the intense reactivity of the immunostaining VEGF suggest metabolic changes of interstitial cell population.

VEGF and its ligands are widely distributed in all the tissue. Particularly in endocrine gland endothelium where it is highly present around fenestrated micro vessels. It has been reported and identified an angiogenic mitogen selective factor for endocrine gland endothelium (EGVEGF) [12,13]. This factor is strongly expressed around Leydig cells that secrete testosterone. It is noteworthy that the intense metabolic activity associated with spermatogenesis and steroid genesis is linked to Leydig cells that are known to be a source of angiogenic and permeability-enhancing factor such as VEGF. Leydig and possibly also testicular cells secrete VEGF and its receptors (VEGFR 1 and 2) are expressed on testicular vessels [5].

Indirect evidences suggest that VEGF could play an important role in testicular physiology and pathology. Häggström Rudolfsson has shown that hCG stimulation causes an increase synthesis of VEGF RNA and VEGF protein [14]. Furthermore hCG treatment has several effects on testicular vessels and induces migration of PMN lymphocytes in testicular post capillary venules causing testicular edema and inflammation-like reaction [15]. In our study the increased intertubular eosinophilic material is probably due to VEGF action on testicular capillary permeability. These tissues are characterized by high permeable, often fenestrated vessels and high endothelial cell turnover.

The hCG treatment causes an increase of Leydig cells producing VEGF and testosterone, whose action is principally expressed in the local tissue, also considering the peculiar testicular micro vessels [14]. Some studies indicate that testicular blood flow and vascular permeability is increased after gonadotropin hCG treatment [1]. VEGF is also known as vascular permeability factor (VPF) and his receptors have been shown in the whole testis. Immunohistochemically VEGF immunoreactivity has been shown in Leydig and Sertoli cells [5] that, as in our study, were immunostained. These results suggest that VEGF has a role as mitogenic and angiogenic factor with an influence on capillaries permeability. VEGF was shown also in adult human epididymis [2]. The role of VEGF in male reproductive tract has been debated. High content of VEGF in human semen suggest an important role of this factor in male fertility [16]. However VEGF over expression on the testis and epididymis in transgenic mice showed severe histopathological abnormalities and caused infertility $[14,17]$.

In our study we found an intense expression of VEGF in Leydig cells after treatment with hCG. Gonadotropininduced production of VEGF from rat and mouse Leydig cells has been reported in vivo [14] and in vitro [18,19].
Furthermore hCG treatment evoked an increase in testicular permeability in experimental varicocele of rats [20]. Thus, Leydig cells might play a role to regulate the angiogenesis and local vascular permeability. A better understanding of VEGF role in the testis could clarify important insight into pathogenesis of other testicular disorders. hCG treatment has been used in the medical treatment of cryptorchidism. The theoretical basis for hormonal therapy is on the hypothesis that in children with undescended testis the hormonal surge that occurs in first six months of life is blunted thus influencing germ cell maturation. Nevertheless its use in the management of cryptorchidism has been debated and potential harmful effects of hormonal therapy on the testis including apoptosis, inflammation and reduced number of germ cells continue to be explored [21]. Cortes and Thorup demonstrated that in one to three year boys with cryptorchidism HCG treatment may be hazardous to germ cells, therefore, they cannot be recommended [9]. Therefore considering the efficacy and the possible side effects of the hormonal treatment, the general use of hCG and GnRH in the treatment of cryptorchidism cannot be further recommended [21-23]. Recently we have conducted in the area of Naples (Italy) a retrospective study on cryptorchidism treatment and we have verified that hormonal therapy is still widely diffused and that it may delay the surgical treatment [24].

In our experimental study in the hCG treated rats, it has been observed a poor differentiation of the seminiferous epithelium, with high Leydig cell evidence and increased intertubular eosinophilic material (Figure 1). This experimental data emphasizes the possible negative effect of hormone therapy on germ cell line and its main action on Leydig cells. The increased synthesis of VEGF, determinated by hCG therapy also highlights the increased cell permeability causing interstitial edema. The role of VEGF on spermatogenesis is unclear. Several findings have revealed several inhibitory effects of VEGF on spermatogenesis [5,17,25]. Furthermore vascular endothelial growth factor expression was increased in testes with varicocele, and was inversely correlated with total motile sperm count and testicular volume, indicating that excessive vascular endothelial growth factor has harmful effects on spermatogenesis in testes with varicocele [26].

These data raise the question of the role of VEGF in male fertility and its implication in the regulation of spermatogenesis and testicular physiopathology [27]. In our study, the immunostained VEGF reaction may have an influence on primary germinative line and therefore on male fertility.

In conclusion, our study demonstrated that hCG stimulation has an action on all male reproductive system. The increased number of Leydig cells and the intense immunostaining reactivity of VEGF suggest an increased in- 
terstitial metabolism. hCG stimulation modifies VEGF expression in the testis, and his role in male fertility has to be long studied.

\section{REFERENCES}

[1] Ergun, S., Kilic, N., Fiedler, W. and Mukhopadhyay, A.K. (1997) Vascular endothelial growth factor and its recaptors in normal human testicular tissue. Molecular and Cellular Endocrinology, 131, 9-20. doi:10.1016/S0303-7207(97)00082-8

[2] Ergün, S., Luttmer, W., Fiedler, W. and Holstein, A.F. (1998) Functional expression and localization of vascular endothelial growth factor and its receptors in the human epididymis. Biology of Reproduction, 58, 160-168. doi:10.1095/biolreprod58.1.160

[3] Reisinger, K., Baal, N., McKinnona, T., Munstedt, K. and Zygmunta, M. (2007) The gonadotropins: Tissue-specific angiogenic factors? Molecular and Cellular Endocrinology, 269, 65-80. doi:10.1016/j.mce.2006.11.015

[4] Ferrara, N. and Davis-Smyth, T. (1997) The biology of vascular endothelial growth factor. Endocrine Reviews, 18, 4-25. doi:10.1210/er.18.1.4

[5] Nalbandian, A., Dettin, L., Dym, M. and Ravindranath N. (2003) Expression of vascular endothelial growth factor receptors during male germ cell differentiation in the mouse. Biology of Reproduction, 69, 985-994. doi:10.1095/biolreprod.102.013581

[6] Thomas, O.D. and Dale, A. (2000) Endothelial signal integration in vascular assembly. Annual Review of Physiology, 62, 649-671. doi:10.1146/annurev.physiol.62.1.649

[7] Christiansen, P., Muller, J., Buhl, S., et al. (1988) Treatment of cryptorchidism with human chorionic gonadotropin or gonadotropin releasing hormone. Hormone Research, 30, 187-192. doi:10.1159/000181058

[8] Bergh, A., Damber, J.E. and Hjertkvist, M. (1996) Human chorionic gonadotropin induced testicular inflammation may be related to increased sensitivity to interleukin1. International Journal of Andrology, 19, 229-236. doi:10.1111/j.1365-2605.1996.tb00467.x

[9] Cortes, D., Thorup, J. and Visfeldt, J. (2000) Hormonal treatment may harm the germ cells in 1- to 3-year-old boys with cryptorchidism. Journal of Urology, 163, 12901292. doi:10.1016/S0022-5347(05)67763-4

[10] Friedman, R.M., Lopez, F.J., Tucker, J.A., King, L.R. and Negro-Vilar, A. (1994) Fertility after cryptorchidism: A comparative analysis of early orchidopexy with and without concomitant hormonal therapy in the young male rat. Journal of Urology, 151, 227-233.

[11] Leon, M.D., Calvo, J.C., Charreau, E.H. and Chemes, H.E. (1990) Developmental changes in testicular interstitial cell populations, LH receptors and in the response to hCG in the rat. International Journal of Andrology, 13, 110-122. doi:10.1111/j.1365-2605.1990.tb00968.x

[12] LeCouter, J., Kowalski, J., Foster, J., Hass, P., et al. (2001) Identification of an angiogenic mitogen selective for endocrine gland endothelium. Nature, 412, 877-884.

\section{doi: $10.1038 / 35091000$}

[13] LeCouter, J., Lin, R. and Ferrara, N. (2002) Endocrine gland-derived VEGF and emerging hypothesis of organspecific regulation of angiogenesis. Nature Medicine, $\mathbf{8}$, 913-917. doi:10.1038/nm0902-913

[14] Rudolfsson, S.H., Wikström, P., Jonsson, A., Collin, O. and Bergh, A. (2004) Hormonal regulation and functional role of vascular endothelial growth factor A in the rat testis. Biology of Reproduction, 70, 340-347. doi:10.1095/biolreprod.103.016816

[15] Bergh, A. and Damber, J.-E. (1993) Vascular controls in testicular physiology. In: deKretser, D.M., Ed., Molecular Biology of the Male Reproductive System, Academic Press Inc., New York, 439-468.

[16] Brown, L.F., Yeo, K., Berse, B., Morgentaler, A., Dvorak, H.F. and Rosen, S. (1995) Vascular permeability factor (vascular endothelial growth factor) is strongly expressed in the normal male genital tract and is present in substantial quantities in semen. Journal of Urology, 154, 576579. doi:10.1016/S0022-5347(01)67114-3

[17] Huminiecki, L., Chan, H.Y., Poulsom, R., Stamp, G., Harris, A.L. and Bicknell, R. (2001) Vascular endothelial cell growth factor transgenic mice exhibit reduced male fertility and placental rejection. Molecular Human Reproduction, 7, 255-264. doi:10.1093/molehr/7.3.255

[18] Anand, R.J.K., Paust, H.-J., Altenpohl, K. and Mukhopadhyay, A.K. (2003) Regulation of vascular endothelial growth factor production by leydig cells in vitro: The role of protein kinase A and mitogen-activated protein kinase cascade. Biology of Reproduction, 68, 1663-1673. doi:10.1095/biolreprod.102.009795

[19] Schwarzenbach, H., Chakrabarti, G., Joachim Paust, H. and Mukhopadhyay, A.K. (2004) Gonadotropin mediated regulation of the murine VEGF expression in MA-10 Leydig cells. Journal of Andrology, 25, 128-139.

[20] Salama, N., Bergh, A. and Damber, J.-E. (2003) The changes in testicular vascular permeability during progression of the experimental varicocele. European Urology, 43, 84-91. doi:10.1016/S0302-2838(02)00501-8

[21] Ludwikowski, B. and González, R. (2013) The controversy regarding the need for hormonal treatment in boys with unilateral cryptorchidism goes on: A review of the literature: European Journal of Pediatrics, 172, 5-8. doi:10.1007/s00431-012-1711-y

[22] Thorsson, A.V., Christiansen, P. and Ritzèn, M. (2007) Efficacy and safety of hormonal treatment of cryptorchidism: Current state of the art. Acta Paediatrica, 96, 628630.

[23] Martin Ritzén, E., Bergh, A., Bjerknes, R., Christiansen, P., Cortes, D., Haugen, S., Jörgensen, N., Kollin, C., Lindahl, S., Läckgren, G., Main, K., Nordenskjöld, A., Rajpert-De Meyts, E., Söder, O., Taskinen, S., Thorsson, A., Thorup, J., Toppari, J. and Virtanen, H. (2007), Nordic consensus on treatment of undescended testes. Acta Paediatrica, 96, 638-643. doi:10.1111/j.1651-2227.2006.00159.x

[24] Papparella, A., Coppola, S., Nino, F., Andrade Barrientos, M. and Gasparini, N. (2013) Epidemiology and treatment of cryptorchidism and retractile testis: Retrospective study 
in the area of Naples. Minerva Pediatrica, 65, 77-82.

[25] Korpelainen, E.I., Karkkainen, M.J., Tenhunen, A., Lakso, M., Rauvala, H., Vierula, M., et al. (1998) Overexpression of VEGF in testis and epididymis causes infertility in transgenic mice: Evidence for non-endothelial targets for VEGF. Journal of Cell Biology, 143, 1705-1712. doi:10.1083/jcb.143.6.1705
[26] Shiraishi, K. and Naito, K. (2008) Involvement of vascular endothelial growth factor on spermatogenesis in testis with varicocele. rtility and Sterility, 90, 1313-1316. doi:10.1016/i.fertnstert.2007.08.030

[27] Hyder, S.M. and Stancel, G.M. (2000) Regulation of VEGF in the reproductive tract by sex-steroid hormones. Histology and Histopathology, 15, 325-334. 